\title{
NETWORK ANALYSIS OF TERRORISM DEFENSE ORGANIZATIONS - A NETWORK APPROACH FOR DEVELOPING PERFORMANCE INDICATORS
}

\author{
Irma Borst, Joan Baaijens, Geleyn R. Meijer \\ LogicaCMG, \\ irma.borst@logicacmg.com;joan.baaijens@logicacmg.com;geleyn.meijer@logicacmg.com \\ THE NETHERLANDS
}

\begin{abstract}
This document presents a newly developed approach for defining performance indicators for policy chains. Policy chains are collaborative networks in the government sector that develop, implement and administrate and/or control public bodies. The developed approach is based on two existing methods that we use frequently in our consultancy practice: a method for defining performance indicators for traditional (not virtual) public organizations and an approach for network analysis. By combining the methods an approach tailored to network organizations is constructed. The approach is being validated by applying it to a policy chain in the terrorism defense domain.
\end{abstract}

\section{INTRODUCTION}

Collaborative Network Organisations (CNOs) correspond to a very active and steadily growing area. These networks are also observed in the government sector and are called policy chains. Policy chains are multiple (governmental) organizations that work together in order to develop, implement, administrate and/or control public policies. Examples of policy chains are immigration administration chain, public safety chain and social security chain.

Policy chains seem to be characterized by a large number of actors that have to cooperate in order to fulfill the joint objective. Information exchange and coordination between the network actors is essential in order to achieve this.

Considering the large number of actors, we experienced that many policy chains struggle with non-transparency of the relationships between organizations in the network. With non-transparency we mean that actors in the network do not have a full overview of all actors involved, (inter)dependencies between actors, direct and indirect relations, formal and informal positions of actors (relative power) and performance of individual actors or of the network as a whole.

In order to overcome these non-transparencies we developed a network analysis tool (Baaijens, 2004) which visualizes different types of relations within a policy chain. The resulting network diagrams provide an insight in the practical dynamics of the day-to-day life in organizations and public policy settings. Specifically it 
enables communication on relation data with third parties and it improved understanding of the impact of embeddedness of individual actors in a network.

Besides the internal problems that involved actors experience as discussed above, we notice that there are external forces, such as accounting for government spending, which drive policy chains towards transparency, performance measurement and performance improvement. Based on existing theories for performance indicator (PI) definition, we developed a practical methodology (roadmap) tailored to public organizations (Wondergem, 2004). This roadmap for defining PIs is not tailored to network organizations. By combining the network analysis tool with this roadmap we developed a methodology which is suitable for policy chains. In order to validate the newly developed method, we will use it during a case study in the domain of terrorism defense organizations.

The case study in which we will apply the method to a policy chain in the terrorism defense domain will deliver relevant input to the ECOLEAD project (Ecolead).

\section{TERRORISM DEFENSE ORGANISATIONS}

Terrorism defense chains consist of two types of organizations:

\section{Intervention teams}

Intervention teams responsible for the fight of terrorism will be event-driven. This means that they are not permanently active, but will show a 'sleeping existence' until action is required. In this stage, members of the chain have to prepare themselves so that their action will be effective (and efficient). During this phase the policy chain can be considered as a Virtual Breeding Environment (VBE). A terrorism intervention team in action can be considered as a (short term) Virtual Organization (VO).

\section{Intelligence organization}

The terrorism intelligence organization responsible for data gathering and information analysis on (potential) terrorists and terrorist events can be considered (after its creation phase) as a longer term organization. The intelligence staff does not belong to one organization but are part of various Dutch Ministries and public bodies and can therefore be classified as a VO.

The behavior of both teams will be completely different. For example communication patterns, information needs, type and dependency on communication facilities will be incomparable. At the same time, the organizations are very much dependent on each other for being effective in their activities.

At the moment, the effectiveness of terrorism defense organizations is a very hot issue. We distinguish four kinds of motives for having PI implemented in terrorism defense organizations (AIVD report, 2004), (Fijnaut, 2004):

1. Improve focus on results and transparency

The Dutch society requires a visible improvement of the results of terrorism defense organizations. In order to achieve improvement of results, responsible managers should have insight in processes that have an effect on results. If they steer on these processes they are able to improve the results. Besides internal 
transparency there is also a need for external transparency, i.e. towards the citizens.

2. Efficiency of processes

Besides the focus on results, the quality of processes should remain subject of attention and management. In times of scarcity (e.g. no unlimited government spending) it is crucial that resources and time are used in an efficient way. Otherwise terrorism defense organization will lose face and citizens will have a reduced perception of safety.

3. Improve cooperation

In a recent report on the National Intelligence and Security Organization (AIVD), it is concluded that cooperation between AIVD and other bodies requires substantial improvement, both on information exchange and analysis and on operational consequences of these activities. Through process management it will become transparent what different actors are providing in the policy chain. After agreement on desired output, it will be easier for a staff member to contribute successfully. Process management will also support achievement of synergies because a chain approach replaces (sub) optimization of individual actors.

4. Quality of processes

It is also concluded that management of AIVD is fragmented and unclear. This can be improved by introducing process management. Description of core processes enables communication, delegation and improvement of processes. This will lead to a 'self-learning' organization because changes of processes will have an effect on organization structure and on systems.

\section{ROADMAP FOR DEFINING PI}

There are many different methods for defining indicators. All methods assume a direct link between the organization's vision \& strategy and indicators. This is visualized in figure 1.

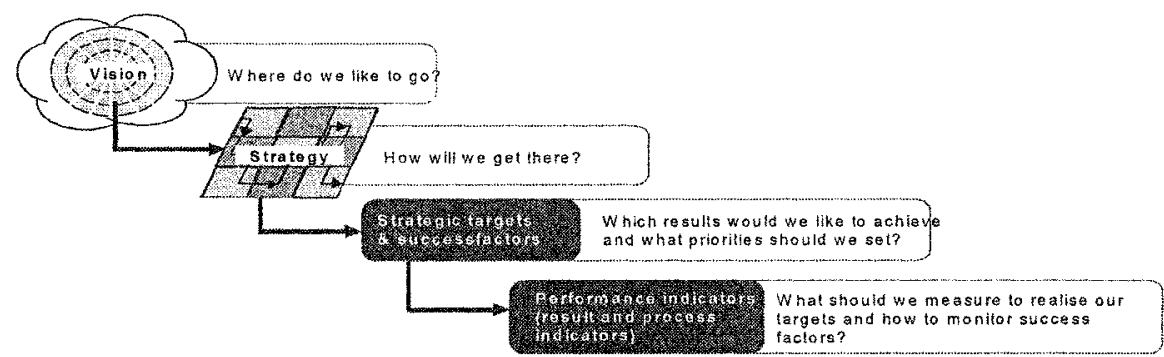

Figure 1 - Relationship performance indicators and vision / strategy

Examples of methods for defining PI are Balanced Scorecard method, strategy trees, process and system models, and methods that are based on customer value (Wondergem, 2004). Wondergem developed a roadmap for defining PI which reflects different basic methods (Wondergem, 2004) and validated this roadmap method within a public body, namely a Dutch police region.

Before describing this method, we would like to point out that PI can be classified in two groups (Wondergem, 2003): 
- Indicators related to processes

Process indicators measure the quality of the process, i.e. is the information gathering process executed by the right person of the intelligence team?

- Indicators related to results

Result indicators refer only to characteristics of the results, i.e. the number of terrorism actions avoided.

In practice there seems to be a natural link between performance indicators and results while process indicators are sometimes forgotten. At the same time, process indicators might be harder to define and measure. Therefore explicitly attention is paid to process indicators in the roadmap.

The roadmap provides a detailed approach for the translation of strategic targets and success factors into PI. The roadmap consists of the following activities:

PI definition method

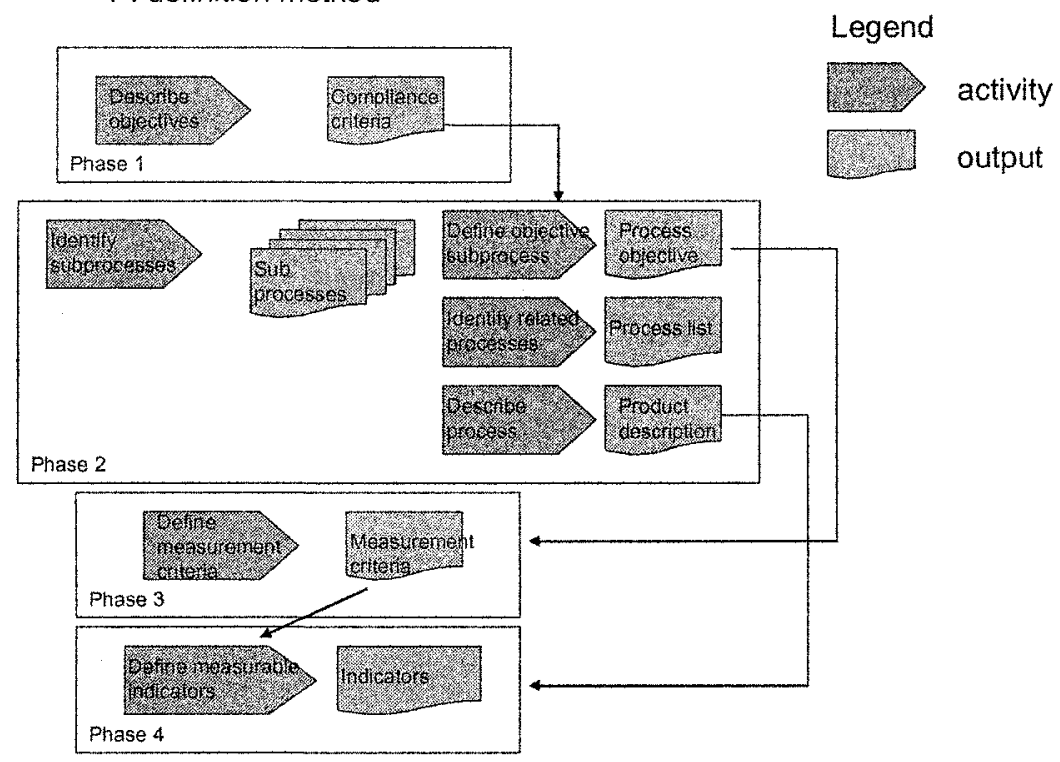

Figure 2 - Roadmap for defining result and process indicators

In phase 1 strategy objectives are described. This results in compliance criteria for processes. Both result oriented and process oriented objectives are included. The framework will be used in phase 2 when determining the objectives for subprocesses. In phase 2 the core process is divided in several sub-processes. For each sub-process, the objectives, underlying processes and the sub-process itself are described. The objectives of the sub-processes and the list of underlying processes are input for the definition of measurement criteria (activities in phase 3 ). Finally the list of products and the measurement criteria are used in the definition of indicators; per product one or more indicators will be defined.

Following the roadmap as described above will not be a guarantee for a successful PI definition process. At the same time the following conditions have to be fulfilled: 
- PI should be developed through negotiation and consensus among key internal and external stakeholders at all steps in the process;

- $\quad$ PI should be simple to convey and broadly understood;

- PI should be based on data that are valid and consistent and that can be verified by third parties when necessary. PI should also be based on established data sources, where possible, in order to maximize credibility and minimize additional workload;

- PI should be established with wide recognition that are certain unavoidable ranges of error in any measurement activity; imposing a false sense of "precision" is counter productive;

- The system of PI should accommodate special circumstances (e.g. unique institutional missions) where possible;

- PI should be kept to the smallest number possible in order to minimize conflicting interactions among the indicators and to maximize the importance of each indicator;

- PI chosen should reflect industry norms and standards, where possible, in order to allow for benchmarking and peer comparison;

- PI system developed should incorporate both quantitative and qualitative measures in order to present the most complete picture of performance possible.

We would like to emphasis the importance of the first statement: PI should be developed through negotiation and consensus of key stakeholders. We believe that defining performance indicators is not exact science, there is room for interpretation. Therefore it is key to search for a shared and transparent definition of indicators. This requires involvement of stakeholders in the definition process: if many different indicators are possible then the selection has to be based on shared vision of stakeholders. Involvement of stakeholders will increase the acceptance of the indicators.

\section{NETWORK GAMES}

In order to apply the PI definition method to network organizations a network perspective on organizations and their environment will be required. This perspective is based on the idea that (organizational) actors are embedded within a network of interconnected relationships that provide opportunities and constraints on behavior (Brass, 2004). Actors can be individual persons, organized units or organizations connected by work flow ties. A network perspective therefore implies a multi-level perspective. In our approach this multi-level perspective is an effective framework for connecting individual actions with actions of organized or collaborative entities.

\subsection{Multi-level aspect}

In defining PI for policy chains, there are at least two levels of analysis. We consider: 


\section{Level of the individual actor}

The orientation of an individual actor in a network is build upon the perception of that actor of the environment in combination with the historical path of experiences and interactions with other actors in a particular organizational field. The perception of the network at the level of one actor is a different perspective than the level of the network as a tangible set of organizations working together. An actor in a network has a structural different kind of interests than the interests of the entire network as a collaborative network.

\section{Level of the network}

The network as a set of actors interconnected by a set of ties has to be distinguished from the actor level. Analysis on the network level is about the size, the density, the composition and the hierarchy of the network.

Information on network level can be reconstructed on basis of the information on individual level. Actors in the network differ in terms of their position towards each other.

\subsection{Network game}

Crucial in the network game method (Baaijens, 2004) is the assumption that information on network level can be constructed on basis of information on individual level. Other essential elements of the method are interactive workshops, visualization of the network structure and the determination of a network score card. A network score card is a standard description of the network in terms of size, composition and hierarchy. We experienced that both the visualization of the network and the score card are powerful tools which increases transparency within the network organization. We distinguish three different formats for the network game:

The first format is a network game on the basis of 'ego nets'. This means that the most prominent actors in a network organization are selected and individually interviewed. A complete set of interviews is processed in a database and analyzed. Next ego-nets step are reconstructed into network structure. The results are presented in a workshop where interviewed actors discuss the network reconstruction. We evaluate the networks with the network score card.

The second format is what we call a 'one actor game'. We select the principal actor from a collaborative network for an interactive workshop. Input of this single actor results in the reconstruction of the network structure and the determination of the network score card.

The third and most advanced format of the network game is the 'multi-actor game'. We select key actors from a virtual collaborative network. These actors provide their (joint) input on network structure and score card during an interactive workshop.

\section{LINKING ROADMAP WITH NETWORK GAME}

By combining the roadmap for defining PI and the network game approach we have a powerful method and road map for constructing and validating performance 
indicators on the level of collaborative networks. Our newly developed approach is visualized in figure 4 .

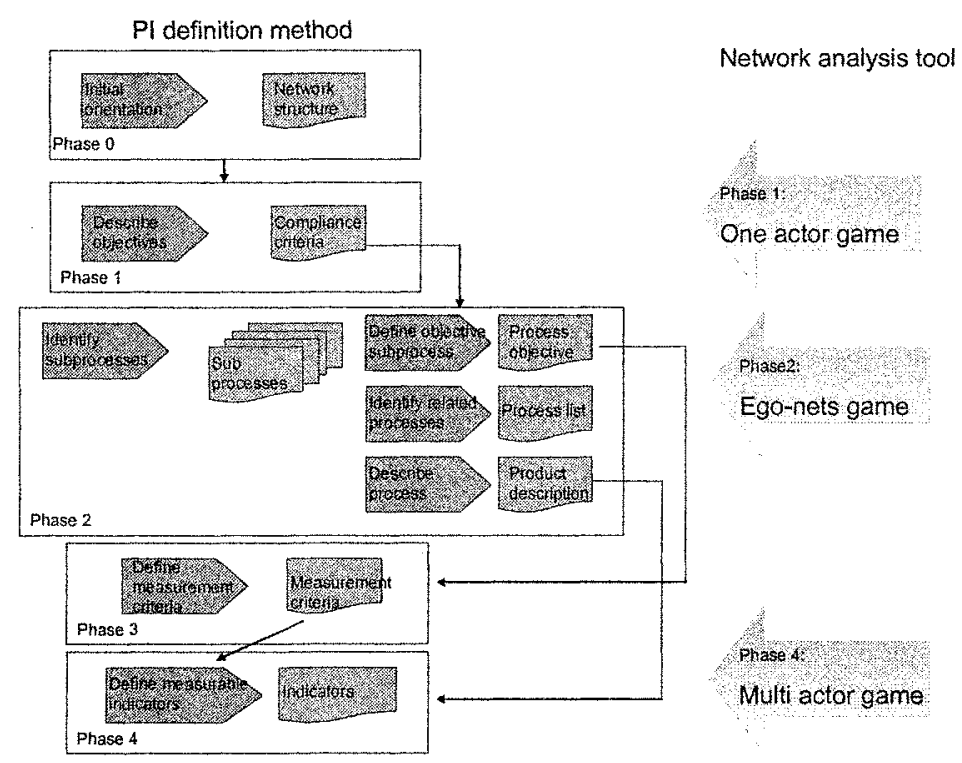

Figure 1 - Roadmap for defining PI tailored to policy chains

\section{Phase 0: Orientation towards actors and network structure}

Phase 0 is new compared to the initial roadmap. We added this step in order to anticipate on the non-transparency that is an observed problem within policy chains. Clarification of the characteristics of the network organization will be required before starting the process of defining PI.

Execution of this phase is mainly through desk research and some selective experts interviews. Output of this phase is a list of relevant actors, a list of domains for which PI can be defined and the choice of a principal actor in the field to work with in phase 1.

Phase 1: Description of objectives - One actor game.

The outcome of phase 0 is the selection of a principal actor, in casu an organization in the field of terrorism defense. With this actor we play the 'one actor network game' as indicated earlier. The output is a graph of the network as a perception of the principal actor. This includes a validated list of actors and their interrelations that structure the collaborative network under study.

Together with the principal actor we also determine the objectives and the compliance criteria. This is based on our assumption that the principal actor will be the best party to oversee the activities of the whole network and therefore able to fulfill this activity.

Phase 2: Description of processes - Ego nets 
The actors in the network resulting from phase 1 will be interviewed in an individual mode. The questionnaire for these interviews will be focused on process objectives, descriptions and underlying processes. The outcome of this phase is a reconstruction of the structure of the collaborative network on the basis of the ego-nets. In reference of this reconstruction we also have the outline of process objectives, lists of processes and the process descriptions.

\section{Phase 3: Definition of measurement criteria}

Based on the results of the previous phase we will prepare measurement criteria independently from the actors.

\section{Phase 4: Definition of indicators - Multi actor game}

In this final phase we validate the reconstruction results and proposed measurement criteria with multiple actors. Next we will define the performance indicators in line with the network structure of the collaborative network organization in the terrorism defense field. As indicated before it is crucial that stakeholders are involved in setting the final PI. The multi-actor game in which stakeholder should reach consensus on the final results is the best option for this phase.

\section{CONCLUSION}

We presented two methods that we are currently using in our consultancy practice. In order to have a method for setting PI applicable to the domain of network organizations, we combined these two methods. We are now in the process of validating the newly developed methodology by using it in a case study in the domain of terrorism defense organizations. Unfortunately we can not yet present results. As a result of the case study we expect to deliver a set of metrics for terrorism defense organizations, practical guidelines for the use of the method (e.g. checklists of relevant issues per phase, process descriptions) and a software tool that processes interview and workshop results in a network score card and a visualization of the network structure. In addition we expect that defined PI for terrorism defense organizations will be examples of metrics applicable to other CNOs.

\section{REFERENCES}

1. Baaijens J.M.J., Lapré L.J. "Network analysis of policy chains in The Netherlands". Paper for the $20^{\text {th }}$ EGOS Colloquium, Ljubljana, Slovenia, July 2004.

2. Brass D.J., Galaskiewicz J., Greve H., Tsai W. "Taking Stock of Networks and Organizations: A Multilevel Perspective". Academy of Management Journal, december 2004

3. Commissie bestuurlijke evaluatie Algemene Inlichtingen- en Veiligheidsdienst. "De AIVD in verandering", november 2004.

4. Ecolead (European Collaborative networked Organizations LEADerschip initiative), www.ecolead.org

5. Fijnaut Prof. dr. C. "De samenwerking tussen de lidstaten van de Europese Unie bij de bestrijding van het internationale islamitische terrorisme". Afscheidsrede Katholieke Universiteit, november 2003

6. www.ibhe.state.il.us/PerformanceIndicators/pdf/item $\% 204 \% 20$ Performance $\% 20$ IndicatorsDec\%202001/pdf.

7. Wondergem B.C.M. "What you measure is what you get - methoden voor het formuleren van prestatie indicatoren". Proceedings van de conferentie Informatiewetenschap, Technische Universiteit Eindhoven, november 2003.

8. Wondergem B.C.M., Vincent N. "Analysing transformation in performance management". Transformation of knowledge, information and data: theory and application, 2004.

9. Wondergem B.C.M., "Doelgericht presteren met processen: indicatoren voor proces en resultaat". Publicatie LogicaCMG/Politie Noord- en Oost Gelderland, januari 2004. 